\title{
Implementation of active management of the third period of childbirth for the prevention of immediate post-partum bleeding in four regional maternity hospitals of Conakry, Guinea
}

\author{
Ousmane Balde ${ }^{1}$, Ibrahima S. Balde ${ }^{2 *}$, Ibrahima Sylla ${ }^{3}$, Fatoumata B. Diallo ${ }^{1}$, \\ Alhassane II. Sow ${ }^{4}$, Sidi M. Haidara ${ }^{5}$
}

\author{
${ }^{1}$ Service Maternite Hospital National, Donka Conakry Guinea \\ ${ }^{2}$ Service Maternite Hospital National, Ignace Deen/University Gamal Abdel Nasser, Conakry Guinea \\ ${ }^{3}$ Service Maternite Hospital National, Ignace Deen, Conakry Guinea \\ ${ }^{4}$ Service Maternite Hospital Regional Labe, Conakry Guinea \\ ${ }^{5}$ Service Maternite Hospital Regional Kindia, Conakry Guinea
}

Received: 11 July 2020

Accepted: 14 August 2020

\section{*Correspondence:}

Dr. Ibrahima S. Balde,

E-mail: baldeisory@yahoo.fr

Copyright: ( $)$ the author(s), publisher and licensee Medip Academy. This is an open-access article distributed under the terms of the Creative Commons Attribution Non-Commercial License, which permits unrestricted non-commercial use, distribution, and reproduction in any medium, provided the original work is properly cited.

\begin{abstract}
Background: The objective of this study was to determine the frequency, skills level of health care service providers; to identify complications and difficulties related to the implementation of AMTPC/GATPA.

Methods: It was about prospective study, descriptive of 6 months ( $1^{\text {st }}$ March to $31^{\text {st }}$ August 2014) carried out in the maternity hospitals of Faranah, Kindia, Mamou and Nzérékoré. It concerned the parturient women who had recently given birth and the personnel that carried out AMTPC/GATPA in these hospitals.

Results: During the study period of 1,254 out of 1,305 births had benefited of AMTPC/GATPA, a frequency of $96.1 \%$. The midwives were the most represented personnel in the implementation of GATPA (44.1\%). In $46.4 \%$ of the cases, the health care service providers acquired this competence from the initial training. The release was obtained in the first trial in $64.9 \%$ cases. The duration of implementation of GATPA was less than 5 minutes in $72.6 \%$ cases. The different stages were respected in $91.5 \%$ cases. Complications were dominated by retention of placental fragments $(10.2 \%)$. Lack of oxytocin was the main difficulty $(36.6 \%)$.

Conclusions: The sustainability of this achievement would depend on the systematic and correct implementation of AMTPC/GATPA at all childbirth attendants and the effective management of oxytocin.
\end{abstract}

Keywords: AMTPC/GATPA, Guinea, Implementation, Maternities

\section{INTRODUCTION}

Immediate post-partum bleeding (HPPB) refers to a blood loss of $\geq 500 \mathrm{CC}$ within 24 hours after childbirth. ${ }^{1-3}$ Uterine atony is the main cause. ${ }^{2,4}$ Its frequency varies: $4.5 \%$ in France; $5.1 \%$ in Canada; $10.8 \%$ in Latin America; $1.4 \%$ in Morocco in, $54 \%$ in Tunisia; $0.2 \%$ in Niger, $4.7 \%$ in Togo, $3 \%$ in Guinea at the National Hospital Donka. ${ }^{5-12}$ It occurs unexpectedly in almost twothirds of pregnant women, even without any identifiable risk and is responsible for more than $50 \%$ of maternal deaths worldwide in less than two hours if it is not taken care of. ${ }^{13,14}$ In sub-Saharan Africa, $47.2 \%$ of maternal deaths are attributable to it. ${ }^{15}$ In addition, it causes significant long-term morbidity. ${ }^{15}$ It can be prevented by GATPA which includes the administration of a tonic utero drug (oxytocin $10 \mathrm{IU}$, the medication of choice); controlled traction of the umbilical cord and uterine massage after delivery. ${ }^{9,14,16}$ GATPA reduces the prevalence of PPH due to uterine atony by almost $60 \%$; 
the need for blood transfusion (with the medical risks, hospitalization and associated costs); and poor health or death. ${ }^{18-20}$ It is an easy intervention, possible at low costs and based on scientific evidence. ${ }^{20,22,23}$ Its establishment requires the presence of a qualified service provider (doctor) at the time of Delivery. ${ }^{24}$ The objectives of the study were to determine the frequency, of skill level of the service providers (Doctors); identify complications and difficulties related to the implementation of GATPA.

\section{METHODS}

\section{Type and duration of the study}

The study was prospective of descriptive type lasting six (6) months from $1^{\text {st }}$ March to $31^{\text {st }}$ August 2014 inclusive.

\section{Characteristics of the population}

\section{Target population}

It was made up of all pregnant women benefiting from services in the maternities of the Regional Hospitals of Mamou, Kindia, Faranah and N'Zérékoré as well as the staff of the said maternities.

\section{Study population}

It consisted of all the parturient referred or not who gave birth in the maternities of the Regional Hospitals of Mamou, Kindia, Faranah and N'Zérékoré and the staff who carried out AMTPC/ GATPA in these structures during the study period.

\section{Selection procedure}

Authors carried out an exhaustive census of all cases of vaginal births that met the selection criteria defined below:

\section{Inclusion criteria}

All parturient whose gestational age was greater than or equal to 22 weeks of amenorrhea, who gave birth vaginally, benefited from AMTPC/GATPA and agreed to participate in the study in these maternities; staff who performed AMTPC/GATPA in these maternities and agreed to participate in the study.

\section{Exclusion criteria}

Women who were admitted in the immediate postpartum period after giving birth in another facility, whether referred or evacuated, and in whom delivery was active in said facility; women who have been evacuated to the ward for total or partial retention of the placenta; parturients who gave birth in these maternities but who did not benefit from active delivery; parturients who gave birth in these maternities who benefited from active delivery but who did not agree to participate in the study; personnel who performed AMTPC/GATPA during the study period but refused to participate in the study.

\section{Data collection procedure}

A collection sheet developed on the basis of the independent variables identified during the operationalization of the dependent variables. Collection media which are the clinical records, the partograph and the delivery register.

\section{Collection techniques}

They were based on observation in the delivery room and documentary review of data collection media.

The parameters studied were frequency; the competences/skills of the service provider; complications and difficulties associated with the implementation of GATPA.

\section{The statistical test}

Compared to the statistical test, the study was purely descriptive therefore there was no statistical test. The different stages of AMTPC/GATPA: the production technique consists of; checking for the absence of another fetus in the uterus then; IM injection of $10 \mathrm{IU}$ of oxytocin immediately after the birth of the child; controlled traction of the umbilical cord during uterine contraction with back pressure on the uterus; and uterine massage after delivery of the deliveries.

\section{RESULTS}

\section{A frequency}

During the period of study, 1,254 out of 1,305 births had received help from GATPA, a frequency of $96.1 \%$.

\section{Competence of service providers (doctors)}

Infection prevention standards (IPS)

Four hundred and forty-eight (448) patients out of 1305 $(34.3 \%)$ had benefited from the correct use of IP standards against $65.7 \%$.

\section{Labor duration}

For 627 delivered out of $1305(48 \%)$ the labor lasted between 6-12 hours, for $27 \%$ less than 6 hours and for $25 \%$, it was less than 6 hours.

\section{Time between expulsion and injection of oxytocin}

Nine hundred and forty-seven (947) delivered out of 1305 $(72.6 \%)$ oxytocin before the $60^{\text {th }}$ second compared to $25.1 \%$ for one minute or more. 
Table 1: Professional status and type of training.

\begin{tabular}{|lll|}
\hline Professional status & Effective & $\%$ \\
\hline Doctor & 144 & 11.0 \\
\hline Midwife & 575 & 44.1 \\
\hline Nurse & 110 & 8.4 \\
\hline Medical assistants & 476 & 36.5 \\
\hline Type of training & \\
\hline Initial training & 605 & 46.4 \\
\hline Structured on the job training & 319 & 24.4 \\
\hline On-site training & 381 & 29.2 \\
\hline
\end{tabular}

\section{Number of trials}

In 847 out of 1305 cases $(64.9 \%)$, the delivery was obtained at the first attempt.

\section{Result}

In 1267 out of 1305 (97.1\%), active delivery was successful against $2.9 \%$ failure.

\section{Duration}

For 947 delivered on $1305(72.6 \%)$ the procedure lasted less than five minutes compared to $25.1 \%$ for 5 to 10 minutes.

\section{Respect for the steps}

In 1194 cases out of 1305 (91.5\%), the GATPA steps were respected against $8.5 \%$.

\section{Tool filling}

For 983 of $1305(75.3 \%)$, the management tools were filled correctly.

Table 2: Complications.

\begin{tabular}{|lll|}
\hline Complications & Effective & $\%$ \\
\hline Break cord & 9 & 0.7 \\
\hline Uterine inversion & 4 & 0.3 \\
\hline Retention of placental fragments & 133 & 10.2 \\
\hline No complication & 1159 & 88.8 \\
\hline
\end{tabular}

\section{Difficulties}

A total 478 out of 1305 childbirths (36.5\%), lacked oxytocin and in 234 cases out of 1305 childbirths (17.9\%), no staff were available.

\section{DISCUSSION}

\section{Frequency}

According to this frequency found in this series varied proportions are noted in the literature: $46 \%$ in Nicaragua;
$84 \%$ in Madagascar; $88.7 \%$ in Zambia; $94 \%$ in six countries of sub-Saharan Africa; $98 \%$ in Niger; $95.6 \%$ in Togo on the other hand, Reyal's series and al. ${ }^{10,11,25-29}$ The management of the $3^{\text {rd }}$ period of childbirth was with systematic oxytocin infusion in the immediate postpartum period followed by broad indications of uterine revisions in the presence of risk factors or early bleeding.

The high frequency in this series would be explained by the fact that on the one hand, all staff are to be trained beforehand and on the other hand, since its integration into the minimum activity package of the maternity, all women who gave birth by basis way generally benefit from active delivery.

\section{Competences/skills of service provider}

In this study group, midwives and Medical assistants got the highest percentages ( $44.1 \%$ and $36.5 \%$ respectively) in the implementation of GATPA. The finding was similar in Madagascar studies with $70.3 \%$ and $68.9 \%$ respectively. ${ }^{26,30}$ For Fenomanana et al the shortage of competent personnel in the prevention and management of post-partum bleeding would be a pre-disposing factor in maternal death. ${ }^{31}$

The result would be justified by the predominance of these listed categories- in this study sites compared to other service providers (doctors and nurses). However, the share of doctors was not negligible.

Initial training had the highest proportion $(46.4 \%)$ in the acquisition of skills in GATPA. According to Linda et al in six sub-Saharan African countries (Ethiopia, Kenya, Madagascar, Mozambique, Rwanda and the United Republic of Tanzania) and Prendeville et al. ${ }^{26,32}$ This proportion was $36 \%$ for all types. This study result would be related to the integration of this skill into the training programs of medical students and midwives for almost 10 years in our country. For this study collective/group, the norms of infection prevention were observed correctly in $34.3 \%$ of cases. However, this observation was $47.1 \%$ and $74 \%$ respectively in Benin and Madagascar. ${ }^{14,30}$ This high frequency of non-compliance with IP rules should both worry us about the risks faced by clients in study centers on the one hand and remind us that infection occupies a good place among the direct causes of maternal deaths. ${ }^{33,34}$ This result would be justified by the incorrect wearing of personal protective equipment by health service providers to direct delivery, noncompliance with the stages of material processing and/or waste disposal. In this study population, $48 \%$ of women who gave birth had a labor time between 6 and 12 hours.

The finding was similar in African literature. ${ }^{8,35}$ This high proportion would be due to the high representativeness of the primi and pauci pares in this study sample. It will be remembered that a long duration of labor in childbirth would be a risk factor for post-partum bleeding due to uterine atony. The $10 \mathrm{IU}$ of oxytocin was administered to 
$72.6 \%$ of our childbirths within the first minute of birth. Linda and Justin et al. ${ }^{28,30}$ In the multi-center study conducted in six countries of sub-Saharan Africa in 2015, $52 \%$ and $21 \%$ respectively in the Madagascar study in 2011 , in contrast to the other authors who recorded the highest proportion after the first minute. ${ }^{27,32}$ For 6 out of 10 births $(64.9 \%)$ of this study group, active delivery was obtained at the first attempt. This is explained on the one hand by the fact that oxytocin (10 IU), administered intramuscularly, is the agent (and the route of administration) to be preferred for the Prevention of PPH in the context of vaginal deliveries do not accompanied by only low risks and on the other, by the mastery of the technique by majority of health service providers of this study structures. ${ }^{36}$ Active delivery was a success for $97.1 \%$ of this study childbirths.

This result was very close to the $97.7 \%$ reported by Linda et al in six sub-Saharan African countries. ${ }^{27}$ It is this that GATPA constitutes a safe intervention, cost-effective and sustainable, more humane and ethical process than the management of complications of PPB, especially for women already suffering from anemia or malnutrition. ${ }^{19,21}$ In $72.6 \%$ of cases, the procedure lasted less than five minutes. The finding was similar in the literature. $^{32}$ It would be due to the rapid action of oxytocin and the controlled traction of the umbilical cord from the first uterine contraction to extract the placenta. $91.5 \%$ of our childbirths, the stages of GATPA were observed. Lower proportions are reported in the literature: $13 \%$ in two Madagascar studies and 0.5 to $32 \%$ in seven developing countries. ${ }^{26,30,37}$ According to Cynthia et al, developing countries do not aim at reducing post-partum bleeding as an achievable goal. ${ }^{37}$ They make little use of active support for the third phase of labor and policies regarding this support are often contradictory. These $8.5 \%$ of non-compliance with the three stages of active delivery were related to the lack of controlled traction of the umbilical cord, counter pressure and lack of uterine massage. For $75.3 \%$ of this study childbirths, the management tools were properly filled. This proportion was $80.5 \%$ in the Saizounou et al series in Benin. ${ }^{14}$ The forgetfulness of CPN notebooks, the lack of motivation of some health service providers could justify this insufficiency.

\section{Complications and difficulties}

The retention of placental fragments had the highest proportion $(10.2 \%)$ in this study population. This finding would be linked to the incomplete execution of steps GATPA by the health service providers on the one hand and the failure of the managers to supervise the activities of the structures/hospitals. For 4 out of 10 childbirths $(36.5 \%)$, lack of oxytocin in this series. This result is superimposed on the $23 \%$ recorded in the multicenter conducted study in six countries of sub-Saharan Africa and $25 \%$ recorded in 55 care facilities in the United Republic of Tanzania but significantly lower than the zero percent out of stock in the Beninese study. ${ }^{14,28}$ By contrast, the availability of oxytocin was, according to WHO, almost universal in seven developing countries. ${ }^{37}$ This study result would be related to lack of correct estimation of needs and the inefficient supply system of oxytocin to maternity hospitals.

\section{CONCLUSION}

The sustainability of this result on the study sites would be at the cost of systematic and correct implementation of GATPA in all childbirths, the effective management of oxytocin and regular supervision of activities.

Funding: No funding sources

Conflict of interest: None declared

Ethical approval: The study was approved by the Institutional Ethics Committee

\section{REFERENCES}

1. WHO recommendations for the prevention and treatment of post-partum bleeding. WHO Library; 2014:1-41.

2. Rath WH. Post-partum bleeding-update on problems of definitions and diagnosis. Acta Obstet Gynecol Scand. 2011;90:421-8.

3. Sentilhes L, Vayssière C, Deneux-Tharaux C, Aya AG, Bayoumeu F, Bonnet MP, et al. Post-partum bleeding: recommendations for clinical implementation text of recommendations. J Obstet Gynecol Reprod Biol. 2014;43:1170-9.

4. POPPHI. Prevention of post-partum bleeding: active management of the third period of childbirth-training of qualified birth attendants: facilitator's Guide. Seattle: PATH; 2008:1-215.

5. Bonnet MP. Post-partum bleeding: epidemiological profile and evaluation of anesthesia and resuscitation practices in France. Human Health Pathology. Pierre et Marie Curie University-Paris VI; 2014:55-64.

6. Joseph KS, Rouleau J, Kramer MS. Investigation of an increase in post-partum bleeding in Canada. BJOG. 2007;114(6):751-43.

7. Bisbis W. Bleeding from delivery to the obstetric gynecology department Laila Maryer of University Hospital Facilitate Ibn Casablanca. Urgentol Med Hope. 2002;82:177-9.

8. Sosac S, Althabeef, Beiizan JM, Buerkens P. Risk factor, for PPH in vaginal deliveries in a latin American population. Gynaecol Obstet. 2009;113(6):1313-9.

9. Laidi BN, Sofiene BM, Mehdi K, Hamed J, Saber T, Hayen M. Severe peripartum haemorrhage in resuscitation at a level 3 Tunisian University Centre: Epidemiology and maternal mortality risk factors. Pan African Med J. 2015;21:277.

10. Kathleen H, Jorge H, Maina B, Youssef, Lani M. Prevention of postpartum hemorrhages: importance of quality improvement. Health Care Improvement Project; 2010:1-8. 
11. Sitti N, Carbonne B. Prevention and management of postpartum hemorrhage at Chu Sylvanus Olympio of Lomé in Togo the review of The Midwife; 2016:3-9. Available at: https://dumas.ccsd.cnrs.fr/dumas01224164/document. Accessed on 20 ${ }^{\text {th }}$ April 2020.

12. Bah OH. GATPA in the prevention of bleeding from delivery to the department of obstetrics gynecology of the National Hospital Donka of the Chu of Conakry. Memory DES Obstet Gynecol FMPOS/UGANC. 2009:57-61.

13. PPHI (Prevention of Post-Partum Hemorrhage Initiative). Prevention of postpartum bleeding: active management of the third period of childbirth. Training of skilled birth attendants. Reference manual, Seattle, PATH; 2008.

14. Saizonou J, Adisso S, Agueh DV, Keita S, Makutode M. Factors associated with the poor quality of the Active management of the third period of childbirth in the maternity hospitals of Dassa Zoumèglazou district in Benin. Int J Biol Chem Sci. 2012;6(2):72637.

15. International Confederation of Midwives, International Federation of Gynecologists and Obstetricians. "Joint statement: management of the third period of labor to prevent post-partum bleeding”. J Midwifery Women Health. 2004;49:767.

16. Hill K, Hermida J, Boucar M, Tawfik Y, Marquez L. Mother-baby package: Implementing safe motherhood in countries. Who/FHE/MSM/Geneva. 1994;94:11.

17. Kemal G, Yusuf O, Varol G, Mustafa K Active management of the third period of labor: a brief overview of key issues. Turk J Obstet Gynecol. 2018;15:188-92.

18. Prendiville WJ, Harding JE, Elbourne DR, Stirrat GM. The Bristol third stage trial: active versus physiological management of third stage of labour. British Med J. 1988;297(6659):1295-300.

19. McCormick ML, Sanghvi HC, Kinzie B, McIntosh N. Preventing postpartum hemorrhage in lowresource settings. Int $\mathbf{J}$ Gynecol Obstet. 2002;77(3):267-75.

20. Hill K, Hermida J, Boucar M, Tawfik Y, Marquez L. Health care improvement project; prevention of postpartum bleeding: importance of quality improvement. USAID; 2010:1.

21. Fogarty L. Is active management of third period of labor cost effective for health facilities? A casecomparison study in Guatemala and Zambia. Baltimore, MD: JHPIEGO. 2005:7.

22. Mai TV, Nguyen T, Luu Y, Huong. Reducing postpartum hemorrhage in Vietnam: assessing the effectiveness of active management of third-stage labor. J Obstet Gynaecol Res. 2006;32:489-96.

23. Prendiville WJ, Elbourne D, Mcdonald SJ. Active versus expectant management in the third period of labor (Cochrane Review), in the Cochrane Library, Issue 3. John Wiley and Sons, Ltd: Chichester, UK; 2003.
24. Prendiville WJ, Elbourne D, McDonald SJ. Active versus expectant management in the third stage of labour. Cochrane Data Syst Rev. 2000:3.

25. Harvey SA, Blandón CW, McCaw-Binns A, Sandino I, Urbina L, Rodriguez C, et al. The Nicaraguan maternal and neonatal health quality improvement group. Bulletin de 1 'Organisation mondiale de la Santé,. 2007;85(10):783-90.

26. Bazant E, Rakotovao JP, Rasolofomanana JR, Tripathi V, Gomez P, Favero R, et al. Quality of care to prevent and treat post-partum bleeding and preeclampsia/ eclampsia: an observation-based assessment in Madagascar hospitals. Trop Med Health. 2013;23:168-75.

27. Vivio D, Fullerton JT, Forman R, Mbewe RK, Musumali M, Chewe PM. Integration of the practice of active management of the third stage of labor within training and service implementation programming in Zambia. J Midwifery Women's Health. 2010;55(5):447-54.

28. Linda B, David C, Pamela L, Gurpreet K, Barbara R, Jim R, Vandana T, et al. On behalf of the quality of maternal and newborn care study group of the maternal and child health integrated program active care of the third period of labor in medical institutions: quality Assessment in six countries of sub-Saharan Africa. World Health Organization Bull. 2015;93:741-816.

29. Reyal F, Deffarges J, Laton D, Blot P, Oury JF, Sibony O. severe post-partum bleeding descriptive study at the Maternity Hospital of HR Debré. J Gynécol Obst Biol Reprod. 2002;31:358-64.

30. Rasolofomanana JR, Rakotovao JP, Bazant E, Tripathi V. Quality of care of the prevention and management of common maternal and newborn complications in health facilities in Madagascar. Baltimore. JHPIEGO. 2011:1-46.

31. Phenomanana M, Riel AM, Rakotomena SD, Andrianjatovo JJ, Andrianampanalinarivo HR. Risk factors for mortality from post-partum bleeding in the maternity Hospital of Befelatanana-University hospital facilitate Antananarivo - Madagascar. J Anesth Resuscit Emerg Med. 2009;1(3):4-7.

32. Prendiville WJ. The Bristol third period trial: active versus physiological management of third period of labor. Br Med J. 1988;29(6659):1295-300.

33. Baldé IS, Baldé O, Diallo MC, Diallo MH, Barry A, Baldé MD, et al. Maternal mortality: socio demographic, etiological aspects and risk factors at the obstetric gynecology department of the Mamou Regional Hospital (Guinea Conakry). Rev Int SC Méd. 2017;19(2):100-4.

34. Baldé O, Baldé IS, Diallo MH, Diallo AB, Diallo $\mathrm{BS}$, Donamou S, et al. Maternal mortality in the Kindia Regional Hospital: epidemiological factors and strategic axes of intervention. Rev Int SC Med. 2014;16(4):61-5.

35. Alihonou E. Bleeding of deliverance: statistical and etiological studies (about 151 cases recorded in 5 years. African Med Pub. 2002;121:8-11. 
36. Dean L, Vyta S, André BL. Active management of the third period of labor: prevention and management of post-partum bleeding. Clin Direct SOGC JOGC. 2009;235:1068-84.

37. Stanton C, Armbruster D, Knight R, Ariawan I, Gbangbade S, Getachew A, et al. Application of active third period labor support in seven developing countries. WHO Bullet. 2009;87:161-244.
Cite this article as: Balde O, Balde IS, Sylla I, Diallo FB, Sow AII, Haidara SM. Implementation of active management of the third period of childbirth for the prevention of immediate post-partum bleeding in four regional maternity hospitals of Conakry, Guinea. Int J Reprod Contracept Obstet Gynecol 2020;9:3563-8. 